\title{
G1P3, an IFN-induced survival factor, antagonizes TRAIL-induced apoptosis in human myeloma cells
}

\author{
Venugopalan Cheriyath, ${ }^{1,2}$ Keith B. Glaser, ${ }^{3}$ Jeffrey F. Waring, ${ }^{3}$ Rachid Baz, ${ }^{2}$ \\ Mohamad A. Hussein, ${ }^{2}$ and Ernest C. Borden ${ }^{1}$ \\ ${ }^{1}$ Center for Hematology and Oncology Molecular Therapeutics and ${ }^{2}$ Multiple Myeloma Research Program, \\ The Cleveland Clinic, Taussig Cancer Center, Cleveland, Ohio, USA. ${ }^{3}$ Cancer Research, Abbott Laboratories, Abbott Park, Illinois, USA.
}

\begin{abstract}
The effectiveness of IFN- $\alpha 2 b$ for human multiple myeloma has been variable. TRAIL has been proposed to mediate IFN- $\alpha 2 b$ apoptosis in myeloma. In this study we assessed the effects of IFN- $\alpha 2 b$ signaling on the apoptotic activity of TRAIL and human myeloma cell survival. While TRAIL was one of the most potently induced proapoptotic genes in myeloma cells following IFN- $\alpha 2 b$ treatment, less than $20 \%$ of myeloma cells underwent apoptosis. Thus, we hypothesized that an IFN-stimulated gene (ISG) with prosurvival activity might suppress TRAIL-mediated apoptosis. Consistent with this, IFN- $\alpha 2 b$ stabilized mitochondria and inhibited caspase-3 activation, which antagonized TRAIL-mediated apoptosis and cytotoxicity after 24 hours of cotreatment in cell lines and in fresh myeloma cells, an effect not evident after 72 hours. Induced expression of G1P3, an ISG with largely unknown function, was correlated with the antiapoptotic activity of IFN- $\alpha 2 b$. Ectopically expressed G1P3 localized to mitochondria and antagonized TRAIL-mediated mitochondrial potential loss, cytochrome $c$ release, and apoptosis, suggesting specificity of G1P3 for the intrinsic apoptosis pathway. Furthermore, RNAimediated downregulation of G1P3 restored IFN- $\alpha 2 b$-induced apoptosis. Our data identify the direct role of a mitochondria-localized prosurvival ISG in antagonizing the effect of TRAIL. Curtailing G1P3-mediated antiapoptotic signals could improve therapies for myeloma or other malignancies.
\end{abstract}

\section{Introduction}

Interferons (IFNs) can result in apoptosis, antiangiogenic effects, and immunomodulation (1-3). Although IFNs have been used for myeloma treatment since 1979 (1-5), their benefit for myeloma patients is still debated. A review by the European Myeloma Research Network identified beneficial effects of IFNs in 3 randomized studies and no effect in 3 others (6). Depending on experimental conditions, IFNs can either stimulate or inhibit cell survival or induce apoptosis in myeloma cells (7-11). Induction of TRAIL (also known as Apo2L) has been proposed to mediate apoptosis induced by IFN- $\alpha$ in myeloma cells and in solid tumors $(9,12,13)$. However, an antagonizing effect for IFNs on TRAILinduced caspase- 8 activation has been identified (10). In several studies, IFN- $\alpha$ protected myeloma cells from dexamethasoneinduced apoptosis $(7,14)$, suggesting antiapoptotic activity for IFNs in myeloma. However, molecular mechanisms for antiapoptotic effects of IFNs in malignancies have remained unclear.

To probe molecular and cellular actions of IFNs on myeloma cells, we assessed its effects on induction of IFN-stimulated genes (ISGs) and on TRAIL-induced apoptotic pathways. Depending on duration of treatment, IFN- $\alpha 2 b$ had a dual role in modulating the balance between myeloma cell survival and death. IFN- $\alpha 2 b$ for 24 hours antagonized TRAIL-induced apoptosis, but after 72 hours, it augmented the apoptotic activity

Nonstandard abbreviations used: $\Delta \Psi$, mitochondrial membrane potential; Cox IV, cytochrome $c$ oxidase IV; HAT, His affinity tag; ISG, IFN-stimulated gene; MNC, mononuclear cell; TMRM, tetramethyl rhodamine methyl ester; WCE, whole-cell extract.

Conflict of interest: The authors have declared that no conflict of interest exists. Citation for this article: J. Clin. Invest. 117:3107-3117 (2007). doi:10.1172/JCI31122. of TRAIL. Because prosurvival or antiapoptotic pathways play a central role in the survival of myeloma cells (15), we hypothesized that induction of an ISG with prosurvival activity might be antagonizing the apoptotic activity of TRAIL. Further analysis identified G1P3 (ISG 6-16) as a gene that antagonized the effects of TRAIL by inhibiting the intrinsic apoptotic pathway through mitochondrial stabilization.

\section{Results}

Marginal effects of IFN- $\alpha 2$ b on myeloma cell viability. Effects of IFN- $\alpha 2 b$ on myeloma cell viability were determined by treating IL-6-independent NCI-H929, RPMI 8226, and U266 cells with increasing concentrations of IFN- $\alpha 2 b$ for 24 or 72 hours. Viability assays identified no inhibitory effects of IFN- $\alpha 2$ b after 24 hours, with marginally reduced viability after 72 hours (Figure 1A). Compared with NCI-H929 and U226 cells, RPMI 8226 cells were more resistant to IFN- $\alpha 2 \mathrm{~b}$. Other IFNs, IFN- $\beta$ and IFN- $\alpha 1 \mathrm{~b}$ (Supplemental Figure 1, A and B; supplemental material available online with this article; doi:10.1172/JCI31122DS1), had a similar lack of effects; the $\mathrm{ED}_{50}$ for IFNs could not be defined under these conditions.

To test whether the marginal effects of IFN- $\alpha 2 b$ on myeloma cell viability resulted from lack of efficient signaling, the kinetics of Stat 1 phosphorylation, a critical downstream target of IFNs, was assessed in RPMI 8226 and U266 cell lines (Figure 1B). Immunoblotting with an anti-phospho-Stat 1 antibody identified increased Stat 1 phosphorylation within 0.5 hours of IFN- $\alpha 2 b$, which was lost as treatment duration progressed (compare lanes 2, 4, and 6). Reprobing with an anti-Stat 1 antibody detected an equal amount of Stat 1 in each lane, confirming that the difference in phosphorylated Stat 1 was not due to an increase in Stat1 (Figure 1B). 
A

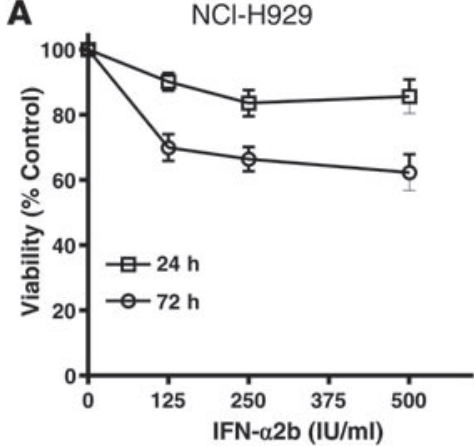

B

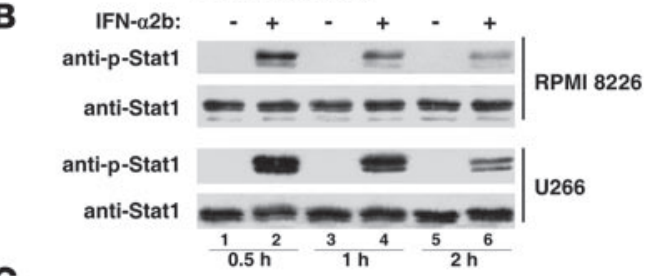

RPMI 8226
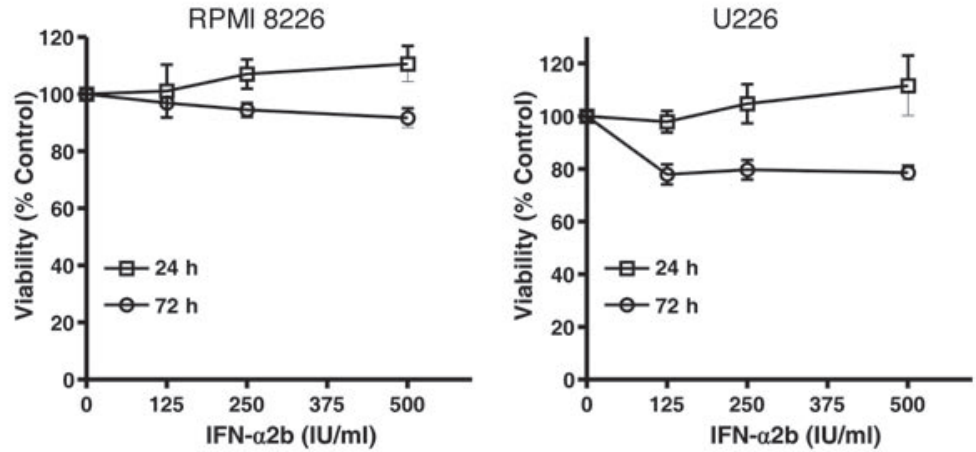

C

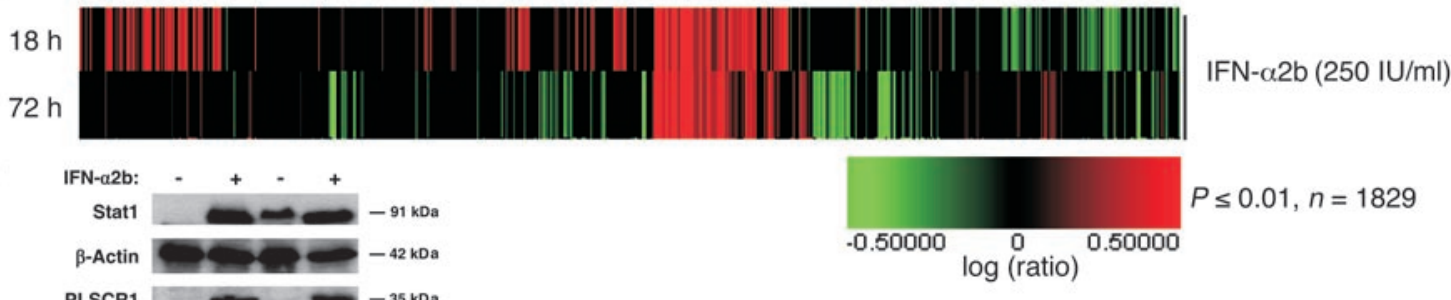

PLSCR1 $-35 \mathrm{kDa}$

$\beta$-Actin $--42 \mathrm{kDa}$

ISG15 $-15 \mathrm{kDa}$

$\beta$-Actin $=-42 \mathrm{kDa}$

G1P3 $-13 \mathrm{kDa}$

$\beta$-Actin $\longrightarrow-42 \mathrm{kDa}$

\section{Figure 1}

Effects of IFN- $\alpha 2 b$ on myeloma cell viability and cell signaling. (A) Effect of IFN- $\alpha 2 b$ on myeloma cell viability. NCI-H929, RPMI 8226, and U266 cells were treated with increasing concentrations of IFN- $\alpha 2 b$ for 24 or 72 hours. Graphs represent viability assay results from 3 independent experiments done with 6 replicates. Each point in the graph represents mean \pm SEM. Student's $t$ test analysis showed $P<0.0001$ for each cell line at all IFN- $\alpha 2$ b concentrations compared with control. (B) IFN- $\alpha 2 b$-induced Stat 1 tyrosine phosphorylation. RPMI 8226 and U266 cells were left untreated or were treated with IFN- $\alpha 2 \mathrm{~b}(250 \mathrm{IU} / \mathrm{ml})$ for $0.5,1$, and 2 hours. Immunoblotting with an anti-phospho-Stat1 antibody identified increased Stat1 phosphorylation. Reprobing with an anti-Stat1 antibody confirmed equal amounts of Stat1. (C) Effects of IFN- $\alpha 2 \mathrm{~b}$ on global gene expression in RPMI 8226 cells. RNA isolated from RPMI 8226 cells left untreated or treated with IFN- $\alpha 2 b$ (250 IU/ml) for 18 or 72 hours was subjected to microarray analysis. (D) IFN- $\alpha 2 b$ induced ISGs in RPMI 8226 and U266 cells. Cells were left untreated or treated with 250 IU/ml of IFN- $\alpha 2 b$ for 24 hours, and $40 \mu \mathrm{g}$ of total protein was analyzed by Western blotting with Stat1-, PLSCR1-, p15-, and G1P3-specific antibodies. $\beta$-Actin levels were assessed as controls.

Since IFNs manifest their actions through ISGs, the effect of IFN- $\alpha 2 \mathrm{~b}$ on global gene expression in myeloma cells was investigated by Affymetrix oligonucleotide array. RPMI 8226 cells were treated with IFN- $\alpha 2 \mathrm{~b}(250 \mathrm{IU} / \mathrm{ml}$ for 18 or 72 hours) for profiling of early and late effects on gene expression; the number and magnitude of gene induction were higher after 18 hours (Figure 1C and Table 1). The subcellular localization and putative function of genes with substantial change in expression were assessed (Table 1). All 18 genes upregulated by greater than 25 -fold were previously identified ISGs. In RPMI 8226 and U266 cells, IFN- $\alpha 2 b$ significantly induced expression of Stat1, phospholipase scramblase R1 (PLSCR1), ISG15, and G1P3 (Figure 1D). Additionally, after IFN- $\alpha 2 \mathrm{~b}$ treatment, mRNA levels of IFITM1, XAF1, G1P3, and
TRAIL were significantly increased in RPMI 8226 cells and in fresh myeloma cells (Table 2). Similar results were obtained with U266 cells and with other isoforms of IFNs (IFN- $\alpha 1 \mathrm{~b}$ and IFN- $\beta$ ) (data not shown). These results suggested that IFN signaling was intact in myeloma cells and IFNs marginal inhibitory effects on viability were not due to a lack of signaling.

IFN- $\alpha 2 b$ antagonized apoptosis induced by TRAIL in myeloma cell lines. Real-time RT-PCR in RPMI 8226 cells identified substantial induction of XAF1 (122.2-fold) and TRAIL (131.4-fold), 2 known proapoptotic ISGs. However, lack of a corresponding decrease in cell viability suggested that RPMI 8226 cells were either not responding to the cytotoxic effects of TRAIL or that IFN- $\alpha 2 b$ was inhibiting TRAIL-induced cell death. Apoptosis of cells left untreated or 
Table 1

Genes upregulated more than 25-fold or downregulated less than 4-fold by IFN- $\alpha 2 b$ in the myeloma cell line RPMI 8226

\begin{tabular}{|c|c|c|c|c|c|c|}
\hline Gene name & $\begin{array}{c}\text { Entrez } \\
\text { Gene ID }\end{array}$ & Description & $\begin{array}{c}\text { Fold } \\
\text { change, } \\
18 \text { hours }\end{array}$ & $\begin{array}{c}\text { Fold } \\
\text { change, } \\
72 \text { hours }\end{array}$ & $\begin{array}{l}\text { Subcellular } \\
\text { location }\end{array}$ & Function \\
\hline ISG20 & 3669 & Interferon stimulated exonuclease gene $20 \mathrm{kDa}$ & 100.0 & 61.3 & Nucleus & Enzyme \\
\hline$M \times 1$ & 4599 & Myxovirus (influenza virus) resistance 1 & 86.2 & 82.8 & Nucleus & Viral response \\
\hline IFI27 & 3429 & Interferon, alpha-inducible protein 27 & 78.7 & 100.0 & Nuclear membrane & Unknown \\
\hline G1P2 & 9636 & ISG15 ubiquitin-like modifier & 78.1 & 54.2 & Extracellular space & ISGylation \\
\hline IFIT1 & 3434 & Interferon-induced protein with tetratricopeptide repeats 1 & 75.5 & 52.1 & Cytoplasm & Unknown \\
\hline IFITM1 & 8519 & Interferon induced transmembrane protein $1(9-27)$ & 65.6 & 57.3 & Plasma membrane & Antiproliferation \\
\hline$B I R C 4 B P$ & 54739 & XIAP associated factor- 1 & 58.7 & 75.0 & Nucleus & Apoptosis \\
\hline G1P3 & 2537 & Interferon, alpha-inducible protein 6 & 50.6 & 36.3 & Unknown & Unknown \\
\hline IFIT3 & 3437 & Interferon-induced protein with tetratricopeptide repeats 3 & 44.0 & 38.5 & Cytoplasm & Growth \\
\hline STAT1 & 6772 & Signal transducer and activator of transcription $1,91 \mathrm{kDa}$ & 38.2 & 37.5 & Nucleus & Transcription \\
\hline GBP1 & 2633 & Guanylate binding protein 1 , interferon-inducible, $67 \mathrm{kDa}$ & 33.7 & 15.1 & Cytoplasm & $\begin{array}{l}\text { Invasion, } \\
\text { proliferation }\end{array}$ \\
\hline OAS1 & 4938 & 2',5'-oligoadenylate synthetase $1,40 / 46 \mathrm{kDa}$ & 32.9 & 11.7 & Cytoplasm & Apoptosis \\
\hline MX2 & 4600 & Myxovirus (influenza virus) resistance 2 (mouse) & 32.8 & 28.0 & Nucleus & Viral response \\
\hline TNFSF10 & 8743 & Tumor necrosis factor (ligand) superfamily, member 10 & 31.1 & 10.8 & Extracellular space & Apoptosis \\
\hline CXCL10 & 3627 & Chemokine (C-X-C motif) ligand 10 & 30.7 & 10.3 & Extracellular space & Chemotaxis \\
\hline CXCL9 & 4283 & Chemokine (C-X-C motif) ligand 9 & 30.0 & 3.7 & Extracellular space & Chemotaxis \\
\hline PLSCR1 & 5359 & Phospholipid scramblase 1 & 29.0 & 25.9 & Plasma membrane & Apoptosis \\
\hline IFITM3 & 10410 & Interferon induced transmembrane protein $3(1-8 \mathrm{U})$ & 27.2 & 20.2 & Plasma membrane & Antiproliferation \\
\hline GNAS & 2778 & GNAS complex locus & -4.1 & 0.0 & Plasma membrane & Apoptosis \\
\hline RGS14 & 10636 & Regulator of G-protein signalling 14 & -4.1 & 0.0 & Cytoplasm & GPCR signaling \\
\hline ALOX5 & 240 & Arachidonate 5-lipoxygenase & -4.3 & 0.0 & Cytoplasm & Apoptosis \\
\hline PLA2G1B & 5319 & Phospholipase A2, group IB (pancreas) & -4.4 & 0.0 & Extracellular space & Apoptosis \\
\hline NFASC & 23114 & Neurofascin homolog (chicken) & -4.4 & 0.0 & Plasma membrane & Adhesion \\
\hline$A O X 1$ & 316 & Aldehyde oxidase 1 & -4.7 & 0.0 & Cytoplasm & ROS metabolism \\
\hline G6PC3 & 92579 & Glucose 6 phosphatase, catalytic, 3 & -4.9 & -2.2 & Unknown & Glycolysis \\
\hline NLGN3 & 54413 & Neuroligin 3 & -5.0 & 0.0 & Plasma membrane & Adhesion \\
\hline FAM49B & 51571 & Family with sequence similarity 49 , member $B$ & -5.4 & 3.0 & Unknown & Unknown \\
\hline
\end{tabular}

Subcellular localization and putative function of target genes were determined from the literature or from Entrez Gene (http://www.ncbi.nlm.nih.gov/entrez/ query.fcgi?CMD=search\&DB=gene). GPCR, G protein-coupled receptor.

treated with TRAIL $(25 \mathrm{ng} / \mathrm{ml})$ or IFN- $\alpha 2 \mathrm{~b}(250 \mathrm{IU} / \mathrm{ml})$ alone or in combination was determined after 24 or 72 hours. IFN- $\alpha 2 b$ alone did not induce apoptosis after 24 hours but increased the percentage of cells undergoing apoptosis from $1.2 \%$ to $18.7 \%$ after 72 hours (Figure 2A). Under the same conditions, TRAIL markedly increased apoptosis from $0.3 \%$ to $46.8 \%$ after 24 hours and $1.2 \%$ to $11.1 \%$ after 72 hours (Figure 2A). Consistent with the hypothesis that an ISG might be inhibiting apoptosis, IFN- $\alpha 2 \mathrm{~b}$ cotreatment for 24 hours markedly reduced TRAIL apoptosis (from $46.8 \%$ to $13.2 \%$ ). However, this early antagonistic effect was lost after 72 hours, and IFN- $\alpha 2 b$ additively increased apoptosis by TRAIL from $11.1 \%$ to $30.1 \%$ (Figure $2 \mathrm{~A}$ ). Consistent with this, IFN- $\alpha 2 \mathrm{~b}$ also antagonized the inhibitory effect of TRAIL on myeloma cell viability at 24 hours but not at 72 hours (Supplemental Figure 1C).

Results of TUNEL assays were confirmed by assessing PARP, MST1, and DFF-45A cleavage. IFN- $\alpha 2 b$ alone did not induce cleavage of any of these molecular parameters of apoptosis (Figure 2B). However, TRAIL induced their cleavage by 6 hours, an effect that continued to 24 hours (Figure 2B). Cotreatment with IFN- $\alpha 2 b$ and TRAIL for 24 hours substantially inhibited PARP, MST1, and DFF-45A cleavage (Figure 2B).

Downregulation of TRAIL receptors (TRAIL R1/DR4 and TRAIL R2/DR5) or upregulation of its decoy receptors (DcR1 and DcR2) could explain the antagonizing effects of IFNs on TRAIL. Howev- er, expression of TRAIL receptor RNAs and proteins in IFN- $\alpha 2 b-$ treated, TRAIL-treated, or cotreated cells was unaltered (Supplemental Figure 2, A and B). In contrast, IFN- $\alpha 2 \mathrm{~b}$ alone induced TRAIL mRNA by 100 -fold and the combination by 131 -fold (Supplemental Figure 2A), suggesting that the effect of IFN- $\alpha 2 b$ was not due to downregulation of TRAIL.

IFN- $\alpha 2 b$ antagonized activation of caspase 3 induced by TRAIL. Since PARP, MST1, and DFF45-A are caspase- 3 substrates (16, 17), effects of IFN- $\alpha 2 b$ on TRAIL-induced caspase activities were assessed in kinetic experiments. Although IFN- $\alpha 2 b$ did not induce either procaspase- 8 or procaspase- 3 cleavage before 20 hours, TRAIL initiated their cleavage after 1 hour (Figure 3A). Maximal cleavage of procaspase- 3 occurred after 3 hours (compare lanes $3,7,11$, and 15), with the levels of the smallest caspase3 cleaved product $(10 \mathrm{kDa})$ highest after 6 hours. The cleavage of procaspase- 3 continued after 20 hours (compare lanes 3 and 16). Although IFN- $\alpha 2 b$ cotreatment slightly reduced the intensity of the $23-\mathrm{kDa}$ cleaved caspase- 8 product after 3 and 6 hours (compare lanes 11 and 12), its antagonizing effect on TRAIL-induced cleavage of procaspase- 3 was more pronounced at 6 hours (compare lanes 12 and 11), with delayed formation of the more active species of caspase 3 (17 kDa and $10 \mathrm{kDa})(18)$.

Caspase-Glo 8 and Caspase-Glo 3/7 assays confirmed results of caspase cleavage assays. Maximal increase in caspase 8 activity, a 


\section{Table 2}

Validation of ISG induction in RPMI 8226 cells and in fresh myeloma cells by IFN- $\alpha 2 b$
ISGs

IFITM

XAF1

G1P3

TRAIL
Fold induction (mean \pm SD)

RPMI 8226

$19.1 \pm 0.6$

$122.1 \pm 3.3$

$49.5 \pm 8.8$

$131.4 \pm 3.6$

\section{Fresh myeloma}

$40.7 \pm 2.2$

$65.6 \pm 1.3$

$219.3 \pm 9.6$

$69.0 \pm 2.4$
Real time RT-PCR was done with gene-specific Taqman probes. The relative expression (fold change) of ISGs in RPMI 8226 and fresh myeloma cells $\left(C D 138^{+}\right.$cells enriched to $>85 \%$ ) treated with IFN- $\alpha 2 b$ for 8 hours was determined with respect to untreated cells. Each value represents the mean $\pm S D$ of 3 independent experiments.

3.7-fold increase over control, was observed 3 hours after TRAIL treatment (Supplemental Figure 3). TRAIL increased caspase-3 activity by 4.1-fold after 3 hours and further increased it to 5.4fold after 6 hours (Supplemental Figure 3). Although IFN- $\alpha 2 \mathrm{~b}$ did not alter TRAIL-induced caspase-8 activity (3.7-fold by TRAIL and 3.0-fold by TRAIL plus IFN- $\alpha 2 \mathrm{~b}$ ), a marked reduction in caspase- 3 activity occurred after 6 hours of cotreatment (5.4-fold by TRAIL alone and 3.4-fold by TRAIL plus IFN- $\alpha 2 \mathrm{~b}$ ). These results demonstrated a greater inhibitory effect of IFN- $\alpha 2$ b on caspase- 3 activity than on caspase- 8 activity.

Mitochondrial membrane potential $(\Delta \Psi)$ has a critical role in caspase- 3 activation by regulating release of cytochrome $c$ into the cytoplasm (19). In the cytoplasm, caspase- 9 activation by cytochrome $c$-Apaf1 complex results in activation of caspase- $3(20,21)$. Incubation of untreated or 24-hour IFN- $\alpha 2$ b-treated cells with tetramethyl rhodamine methyl ester (TMRM), a probe used for measuring $\Delta \Psi$, resulted in higher fluorescence intensity (right shift on $x$ axis) (Figure 3B). In apoptotic cells, where $\Delta \Psi$ was lost, TMRM should result in lower fluorescence; 24-hour treatment with TRAIL lowered the $\Delta \Psi$ in $73 \%$ of cells. However, IFN- $\alpha 2 \mathrm{~b}$ cotreatment for 24 hours reduced the percentage of cells with low $\Delta \Psi$ from $73 \%$ to $56.1 \%$ (Figure $3 \mathrm{~B}$ ), suggesting a mitochondrial stabilizing effect for IFN- $\alpha 2 b$. As treatment duration progressed to 72 hours, IFN- $\alpha 2 \mathrm{~b}$ alone lowered the $\Delta \Psi$ of $41.6 \%$ of cells (Figure 3B, bottom row), which was further increased to $80.3 \%$ in combination with TRAIL (Figure 3B).

The effects of prolonged treatment with IFN- $\alpha 2 \mathrm{~b}$ on intrinsic and extrinsic apoptosis signaling in RPMI 8226 cells were investigated by assessing cleavage of caspase-8, caspase-3, and PARP after 72 hours of treatment. IFN- $\alpha 2 b$ slightly increased the cleavage of caspase-8, caspase-3, and PARP (Figure 3C, lane 2). More importantly, as in early time points, it did not antagonize TRAIL-induced cleavage of either caspase-3 or PARP but enhanced cleavage of caspase-8, caspase-3, and PARP (Figure 3C).

IFN- $\alpha 2 b$ antagonized reduction of fresh myeloma cell viability and $\Delta \Psi$ induced by TRAIL. The effects of IFN- $\alpha 2 \mathrm{~b}$ and TRAIL on the viability of fresh myeloma cells were studied in mononuclear cells (MNCs) isolated from 6 myeloma patients. One-way repeated-measures ANOVA followed by pairwise multiple comparison using the Holm-Sidak method for different treatments showed that IFN- $\alpha 2 b$ had no marked effect on $\mathrm{CD}_{138^{+}}$cell viability either at 62.5 or $250 \mathrm{IU} / \mathrm{ml}$ after 24 hours (Table 3 ). However, TRAIL significantly reduced the $\mathrm{CD}_{138}{ }^{+}$cell viability from $100 \%$ (control) to $76.20 \%(P<0.001)$. As in cell lines, IFN- $\alpha 2 b$ antagonized the effect of TRAIL on fresh myeloma cells during this time. Compared with TRAIL alone, combination treatment with either $62.5 \mathrm{IU} / \mathrm{ml}$ or $250 \mathrm{IU} / \mathrm{ml}$ of IFN- $\alpha 2 \mathrm{~b}$ resulted in $101.32 \%(P<0.001)$ or $94.33 \%(P<0.001)$ viable CD $138^{+}$cells, respectively.

To test whether IFN- $\alpha 2 b$ mediates its antagonizing effects on TRAIL in fresh myeloma cells by preserving their mitochondrial stability, we assessed $\Delta \Psi$ of $\mathrm{CD} 138^{+}$cells enriched to greater than $85 \%$ from 2 patients. Compared with untreated cells, TRAIL decreased the $\Delta \Psi$ of CD $138^{+}$cells from $8.98 \%$ to $23.94 \%$ in sample 1 and $13.86 \%$ to $25.35 \%$ in sample 2 (Figure $4 \mathrm{~A}$ ). Although IFN- $\alpha 2 \mathrm{~b}$ alone did not affect $\Delta \Psi$, it antagonized TRAIL-induced loss of $\Delta \Psi$, resulting in $5.12 \%$ (sample 1 ) and $11.76 \%$ (sample 2) cells with low $\Delta \Psi$ (Figure 4A).

As in cell lines, IFN- $\alpha 2 b$ markedly increased the expression of ISGs including G1P3 in fresh myeloma cells (Figure 4B). Since G1P3 was highly induced both in cell lines and in fresh myeloma cells and has a putative mitochondrial localization sequence in its $\mathrm{N}$ terminal, the role of G1P3 in mediating IFN- $\alpha 2$ b's antagonistic effect on apoptosis was investigated.

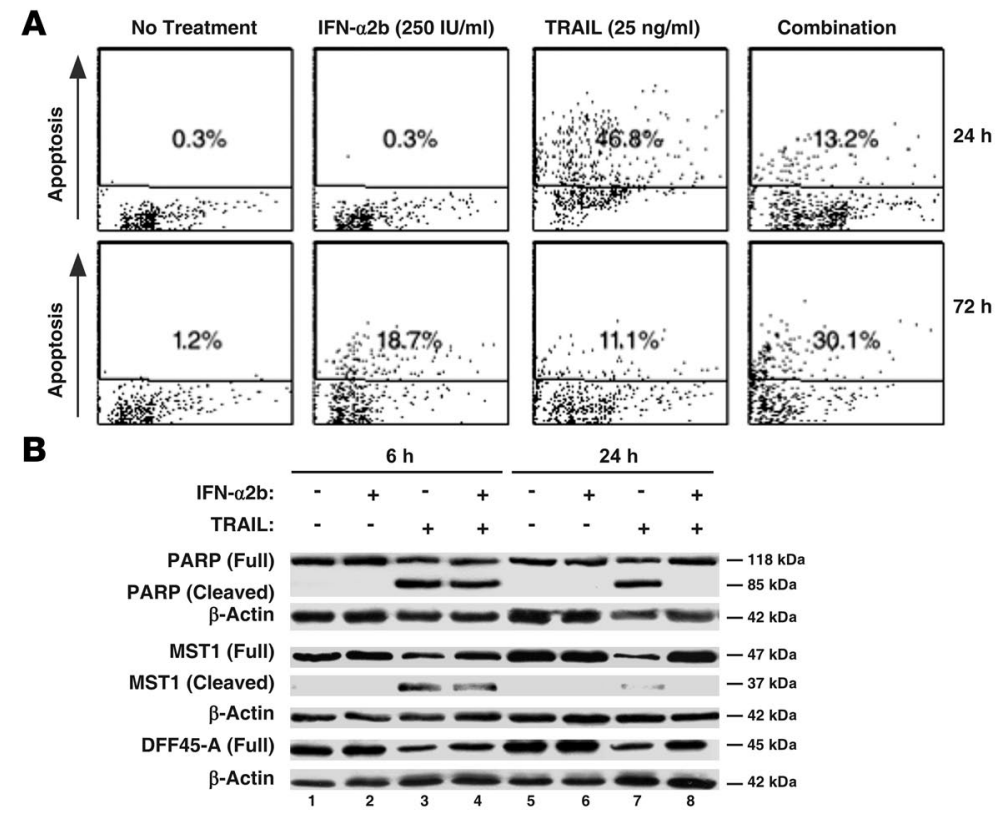

Figure 2

IFN- $\alpha 2 b$ exerts dual effects on TRAIL-induced myeloma cell apoptosis. (A) IFN- $\alpha 2 b(250 \mathrm{IU} / \mathrm{ml})$ cotreatment for 24 hours antagonized TRAIL-induced (25 $\mathrm{ng} / \mathrm{ml}$ ) apoptosis (top panel). However, 72-hour cotreatment additively increased the apoptotic index (bottom panel). Dot plot represents the data from 1 of 3 independent experiments, where 10,000 events were collected for each treatment using a FACS analyzer. Similar results were obtained in 2 other experiments. (B) IFN- $\alpha 2 b$ antagonized TRAIL-induced cleavage of caspase- 3 substrates. WCEs from untreated or IFN- $\alpha 2 b-$, TRAIL-, or IFN- $\alpha 2 b$ plus TRAIL-treated RPMI 8226 samples were subjected to immunoblot analyses to assess PARP, MST1, and DFF 45-A cleavage. The membrane was reprobed with a $\beta$-actin antibody to confirm equal loading of proteins. 
A

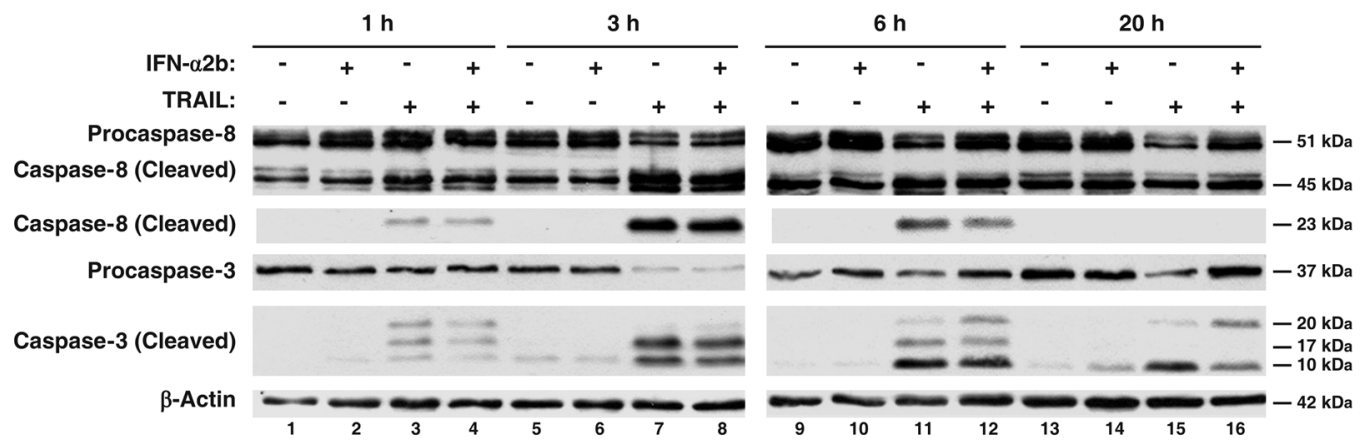

B No Treatment

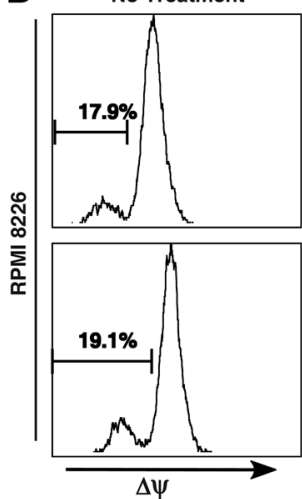

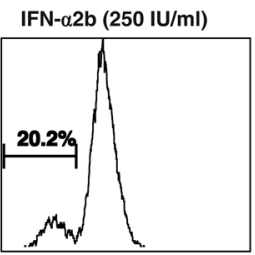
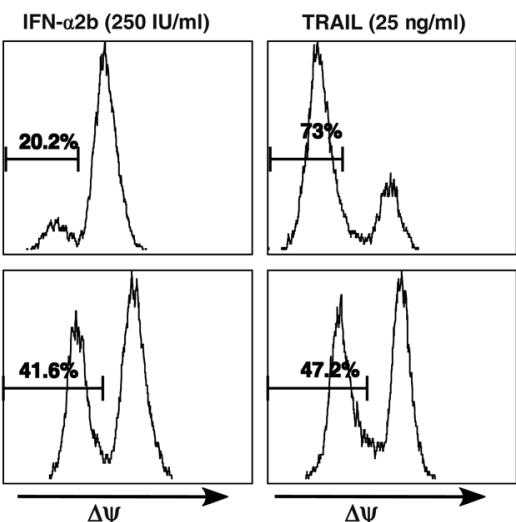

IFN- $\alpha 2 b+$ TRAIL

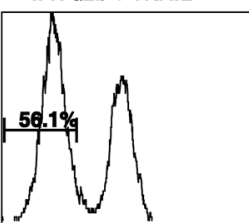

$24 \mathrm{~h}$

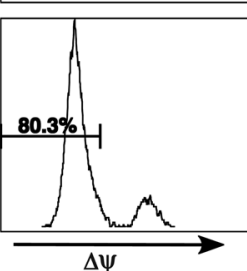

$72 \mathrm{~h}$
C

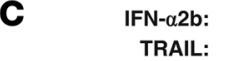

Procaspase-8 Caspase-8 (Cleaved) Caspase-8 (Cleaved)

Procaspase-3

Caspase-3 (Cleaved)
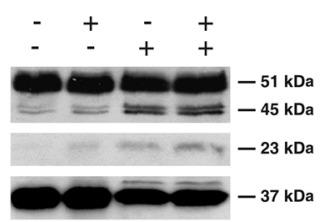

PARP (Full)

PARP (Cleaved)

$\beta$-Actin

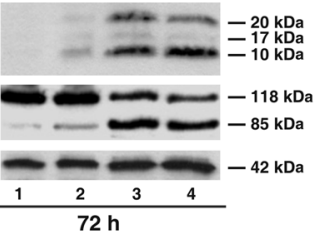

Figure 3

Effects of IFN- $\alpha 2 b$ on TRAIL-induced activation of caspases and $\Delta \Psi$. (A) IFN- $\alpha 2 b$ antagonized TRAIL-induced caspase-3 cleavage. RPMI 8226 cells were treated with IFN- $\alpha 2 b(250 \mathrm{IU} / \mathrm{ml})$, TRAIL $(25 \mathrm{ng} / \mathrm{ml})$, or both in combination. Immunoblots of WCEs after 1-, 3-, 6-, and 20-hour treatments were analyzed for caspase- 8 and caspase- 3 cleavage. Reprobing with $\beta$ - actin antibody showed equal loading. Two independent experiments showed similar results. (B) IFN- $\alpha 2 \mathrm{~b}$ antagonized TRAIL-induced loss of $\Delta \Psi$. $\Delta \Psi$ of untreated or treated cells was measured with TMRM reagent after 24 or 72 hours. Histograms represent results from 1 of 3 independent experiments, where 10,000 events were collected for each treatment using a FACS analyzer. (C) IFN- $\alpha 2 \mathrm{~b}$ augmented TRAIL-induced extrinsic and intrinsic apoptosis signaling at $72 \mathrm{hours}$. WCEs ( $30 \mu \mathrm{g}$ ) from RPMI 8226 cells left untreated or treated with IFN- $\alpha 2 b(250 \mathrm{IU} / \mathrm{ml})$, TRAIL $(25 \mathrm{ng} / \mathrm{ml})$, or both in combination for 72 hours were analyzed for caspase-8, caspase-3, and PARP cleavage. Equal sample loading was confirmed by reprobing with $\beta$-actin antibody.

Constitutively expressed G1P3 localized into mitochondria in RPMI 8226 cells. Time course experiments in RPMI 8226 cells revealed that IFN- $\alpha 2 b$ induced higher expression of G1P3 protein at 24 hours than at 48 and 72 hours (Figure 5A), a finding correlated temporally with lower apoptosis and preservation of $\Delta \Psi$. If IFN- $\alpha 2 b-$ induced G1P3 protected myeloma cells from apoptosis through stabilized mitochondria, then constitutive expression of G1P3 was postulated to induce resistance. Hence, overexpression studies were carried out. Sequences of 12 clones selected during cDNA cloning were aligned with the shortest isoform of the splice variant G1P3a (data not shown; GenBank accession number NM_002038.3), suggesting that G1P3a was the major G1P3 isoform induced by IFN$\alpha 2 b$ in RPMI 8226 cells. G1P3a cDNA was subcloned 3' to a His affinity tag (HAT) sequence in a PQCXIP vector (Figure 5B). RPMI 8226 cells were transduced with either empty vector (pQCXIP), Hat expression vector (HAT), or Hat-G1P3 fusion expression vector (HAT-G1P3), and single-cell clones were isolated. RT-PCR with HAT and G1P3 primers showed the expected 397-bp HAT-G1P3 amplicon in 7 of 8 clones (data not shown).

Real-time RT-PCR identified the highest expression of G1P3 in clone 17 (1,283-fold), followed by clones 7 (912-fold) and 5 (219fold) (Supplemental Figure 4A). Since a difference in expression of TRAIL receptors or TRAIL could influence sensitivity of G1P3 clones to TRAIL or IFNs, HAT and HAT-G1P3 clones with similar levels of TRAIL receptors and TRAIL were identified (Supplemental Figure 4B). HAT-G1P3 clone 5 was selected for functional studies because it had a G1P3 expression level similar to that of IFN-treated cells (Figure 5C and Supplemental Figure 4B) and had levels of TRAIL receptors similar to those of the vector-transduced cells (Figure 5D). Immunoblotting with a purified anti-G1P3 antibody recognized a $17-\mathrm{kDa}$ and a $13-\mathrm{kDa}$ band in whole-cell extracts (WCEs) of clone 5 (Figure 5C). The 13-kDa band comigrated with G1P3 in IFN- $\alpha 2 \mathrm{~b}$-treated cells (positive control), and both bands were absent in the HAT clone.

Subcellular localization of G1P3 was examined by assessing G1P3 distribution in PQCXIP, HAT, and HAT-G1P3 cell fractions (Figure 5E). Anti-G1P3 antibody did not recognize any specific bands in cytoplasmic fractions. However, G1P3-specific 17-kDa and $13-\mathrm{kDa}$ bands were detected only in the mitochondrial fractions of HAT-G1P3 cells (Figure 5E, lane 5). Reprobing of the blots with cytochrome $c$ oxidase IV (Cox IV, a marker for mitochondria) and $\beta$-actin antibodies detected most of the Cox IV in the mitochondrial fraction and $\beta$-actin in the cytoplasmic fraction, indicating purity of subcellular fractions (Figure 5E).

Constitutively expressed G1P3 preserved $\Delta \Psi$ and antagonized TRAILmediated caspase-3 activation. To determine whether ectopic expres- 
Table 3

Effects of IFN- $\alpha 2 b$, TRAIL, or both in combination on CD138+ cell number

\begin{tabular}{|c|c|c|c|c|c|c|}
\hline & \multicolumn{6}{|c|}{$\%$ Survival of CD138+ cells over control ${ }^{A}$} \\
\hline & No treatment & IFN- $\alpha 2 b(62.5 \mathrm{IU} / \mathrm{ml})$ & IFN- $\alpha 2 b(250 \mathrm{IU} / \mathrm{ml})$ & TRAIL (400 ng/ml) & Combination 1 & Combination 2 \\
\hline Patient 1 & 100.00 & 112.15 & 92.52 & 78.04 & 111.68 & 92.97 \\
\hline Patient 2 & 100.00 & 100.00 & 109.09 & 84.85 & 115.15 & 113.04 \\
\hline Patient 3 & 100.00 & 94.09 & 97.20 & 89.70 & 100.54 & 94.58 \\
\hline Patient 4 & 100.00 & 73.17 & 76.22 & 47.56 & 91.40 & 84.12 \\
\hline Patient 5 & 100.00 & 109.09 & 100.00 & 72.73 & 100.00 & 90.91 \\
\hline Patient 6 & 100.00 & 90.36 & 91.57 & 84.34 & 89.16 & 90.36 \\
\hline Mean & 100.00 & 96.48 & 94.43 & $76.20^{\mathrm{B}}$ & $101.32^{\mathrm{C}}$ & $94.33^{C}$ \\
\hline SEM & 0.00 & 5.78 & 4.46 & 6.22 & 4.27 & 4.02 \\
\hline
\end{tabular}

AThere was a statistically significant difference between treatments $(P \leq 0.001)$. BSignificantly different from all other treatments $(P \leq 0.001)$. CSignificantly different from TRAIL treatment $(P \leq 0.001)$. Combination 1 , IFN- $\alpha 2 b(62.5 \mathrm{IU} / \mathrm{ml})+$ TRAIL $(400 \mathrm{ng} / \mathrm{ml})$; Combination 2 , IFN- $\alpha 2 \mathrm{~b}(250 \mathrm{IU} / \mathrm{ml})+\mathrm{TRAIL}(400 \mathrm{ng} / \mathrm{ml})$.

sion of G1P3 could confer resistance to TRAIL-mediated change in $\triangle \Psi$, HAT-G1P3 and HAT clones were treated with TRAIL $(25 \mathrm{ng} / \mathrm{ml})$ for 16 hours. A marked increase in the percentage of vector-transduced cells with low $\Delta \Psi(31.43 \%$ in untreated versus $59.0 \%$ in treated) compared with little effect on $\Delta \Psi$ in HAT-G1P3 cells ( $22.5 \%$ in control versus $31.2 \%$ in treated) was observed (Figure $6 \mathrm{~A})$. In cytochrome $c$ release assays, compared with an isotype matched FITC-conjugated IgG control antibody, a cytochrome $c$-specific antibody markedly increased fluorescence in untreated cells, suggesting mitochondrial confinement of cytochrome $c$ in most cells (Figure 6B). TRAIL $(25 \mathrm{ng} / \mathrm{ml})$ treatment for 16 hours markedly reduced signal intensity in HAT expressing cells due to the release of cytochrome $c$ into cytoplasm (Figure 6B, left panel). Under these conditions, approximately $50 \%$ of HAT-G1P3 cells retained cytochrome $c$ in mitochondria, and this resulted in higher signal intensity (Figure 6B, right panel). Caspase-3 assay results identified a 4-fold increase in caspase-3 activity in HAT cells but not in HAT-G1P3 cells upon TRAIL treatment (data not shown).

Ectopic expression of G1P3 conferred resistance to cytotoxic and apoptotic activity of TRAIL in myeloma cells. HAT and HAT-G1P3 cells were compared to determine the effect of G1P3 on TRAILinduced apoptosis. TRAIL $(50 \mathrm{ng} / \mathrm{ml})$ treatment for 24 hours markedly increased apoptosis (from $4 \%$ to $77.5 \%$ ) of HAT cells, and higher concentrations $(100 \mathrm{ng} / \mathrm{ml})$ resulted in a further
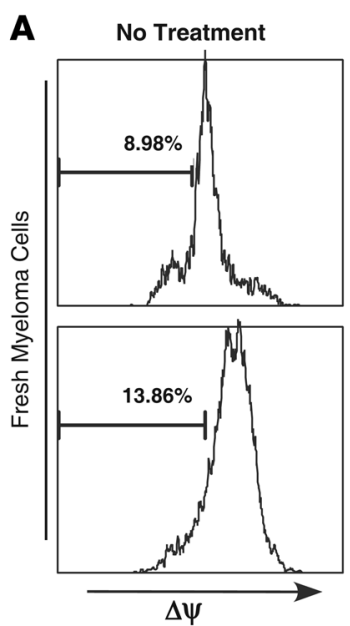

B

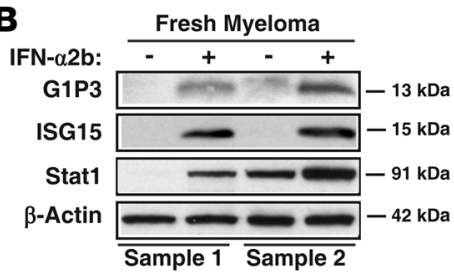

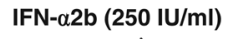
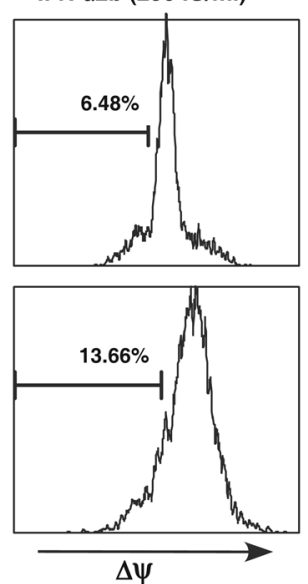
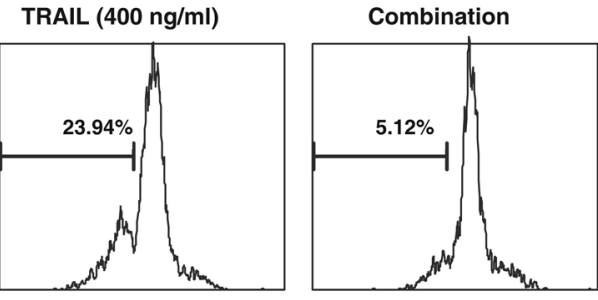

Sample 1
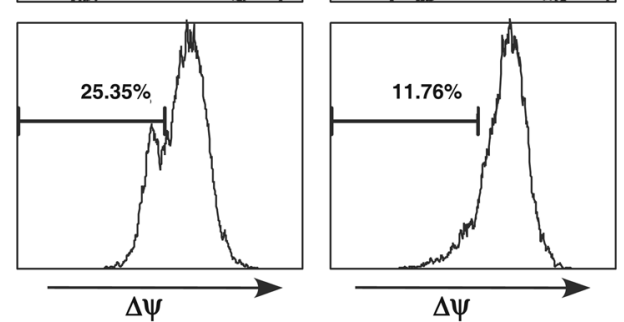

Sample 2

\section{Figure 4}

Effects of IFN- $\alpha 2 b$, TRAIL, and both in combination on the $\Delta \Psi$ of fresh myeloma cells enriched from bone marrow aspirates. (A) CD138+ cells (>85\% enriched) from bone marrow aspirates of 2 patients were subjected to IFN- $\alpha 2 \mathrm{~b}(250 \mathrm{IU} / \mathrm{ml})$, TRAIL $(400 \mathrm{ng} / \mathrm{ml})$, or both in combination for 24 hours, and $\Delta \Psi$ was assessed using a TMRM reagent. (B) IFN- $\alpha 2 b$ induced ISGs in fresh myeloma cells. Fresh myeloma cells were left untreated or treated with $250 \mathrm{IU} / \mathrm{ml}$ of IFN- $\alpha 2 \mathrm{~b}$ for 24 hours, and $30 \mu \mathrm{g}$ of total protein was analyzed by Western blotting with Stat1-, PLSCR1-, p15-, and G1P3-specific antibodies. $\beta$-Actin levels were assessed as controls. 


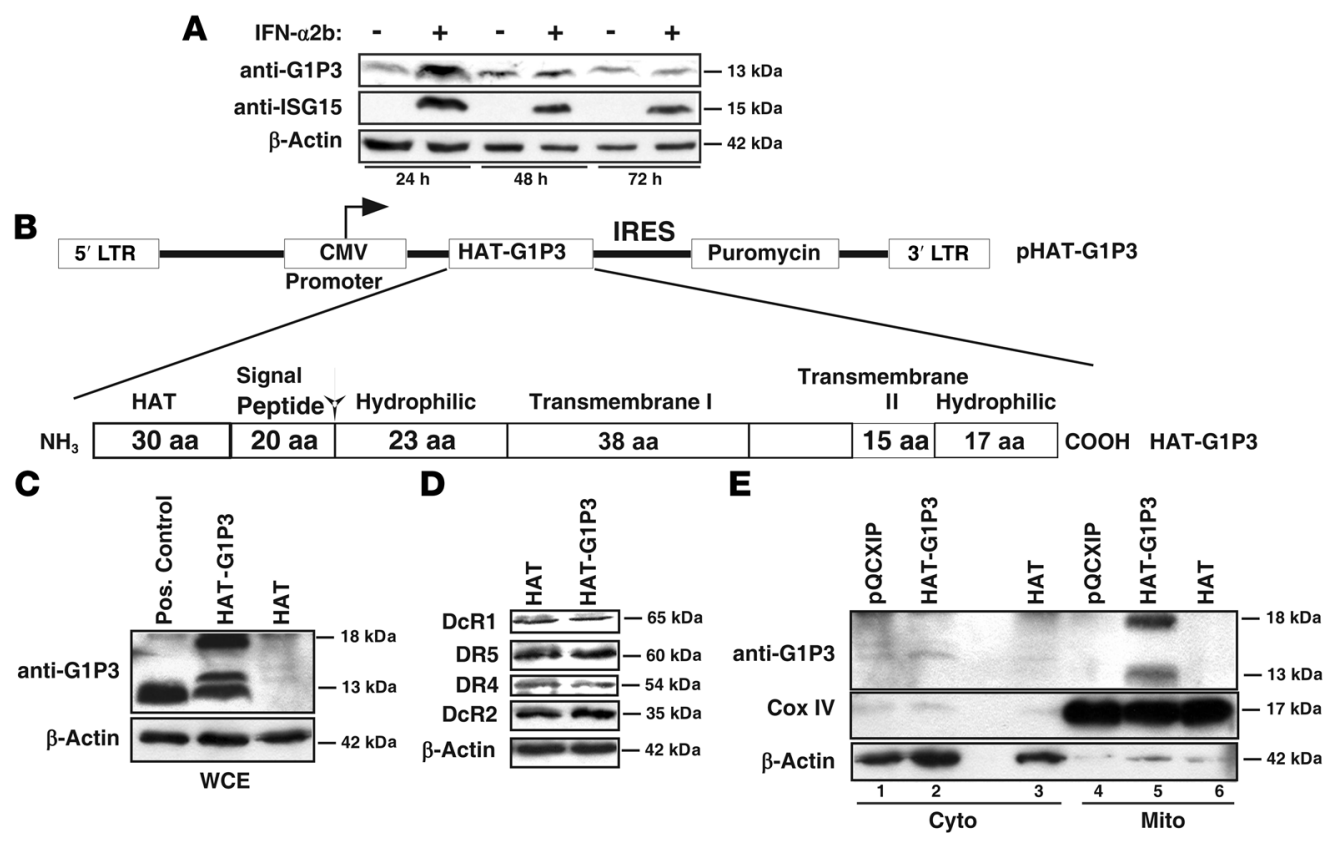

Figure 5

Ectopically expressed G1P3 localized into mitochondria. (A) Relative induction of G1P3 protein in RPMI 8226 cells by IFN- $\alpha 2 b$. WCEs from cells left untreated or treated with IFN- $\alpha 2 \mathrm{~b}(250 \mathrm{IU} / \mathrm{ml})$ for 18,48 , and 72 hours were immunoblotted with an anti-G1P3 antibody. $\beta$-Actin was used as a loading control. (B) Schematics of G1P3 expression vector. HAT at N-terminal and putative structural elements derived from primary amino acid sequence analysis with protean software (Lasergene Inc.) are shown. The arrow indicates the cleavage site, which is located following a putative mitochondrial localization signal peptide of 20 amino acids. (C) Ectopic expression of HAT-G1P3 fusion protein in RPMI 8226 cells. AntiG1P3 antibody specifically recognized a 13-kDa band in the positive control (treated with $250 \mathrm{IU} / \mathrm{ml}$ of IFN- $\alpha 2 \mathrm{~b}$ ) and 13- and 17-kDa bands in HAT-G1P3 lysates. (D) Relative expression of TRAIL receptors in HAT or HAT-G1P3 clones. WCEs $(30 \mu \mathrm{g})$ from untreated or IFN- $\alpha 2 \mathrm{~b}-$ treated $(250 \mathrm{IU} / \mathrm{ml})$ RPMI 8226 cells were immunoblotted with DR4, DR5, DcR1, and DcR2 antibodies. $\beta$-Actin was used as a loading control. (E) Mitochondrial localization of constitutively expressed G1P3. Immunoblotting of cytoplasmic (Cyto) and mitochondrial (Mito) fractions of pQCXIP, HAT, or HAT-G1P3 cells with anti-G1P3 antibody showed the localization of G1P3 in mitochondrial fractions (top panel). Reprobing with anti-Cox IV (middle panel) and $\beta$-actin antibodies (bottom panel) confirmed the purity of subcellular fractions.

increase to 93.6\% (Figure 7A). HAT-G1P3 cells were resistant to TRAIL-induced apoptosis. Although $100 \mathrm{ng} / \mathrm{ml}$ of TRAIL did cause a slight increase in apoptosis of HAT-G1P3 cells at 24 hours (16.3\%) and 48 hours (4.2\%) (Figure 7A), it was markedly lower than that of HAT cells.

To assess effects of G1P3 on mitochondria-independent cell death, the sensitivity of HAT and HAT-G1P3 cells to bortezomib, an agent that causes cell death primarily by inhibiting $26 \mathrm{~S}$ proteasome, was quantified. As expected, G1P3-overexpressing cells were resistant to TRAIL (Figure 7B) and IFN- $\alpha 2 \mathrm{~b}$ (Figure 7C). In contrast, bortezomib had similar $\mathrm{ED}_{50}$ in both HAT and HATG1P3 cells (Figure 7D), suggesting that G1P3 overexpression was specific for cell death pathways wherein mitochondrial perturbation has a major role.

Downregulation of G1P3 sensitized myeloma cells to IFN- $\alpha 2 b$-induced apoptosis. To test whether downregulation of G1P3 will sensitize myeloma cells to IFN- $\alpha 2 b$, RNAi studies were conducted. Since very high transfection efficiency could be achieved in U266 cells (72\% GFP-positive cells compared with 16\% in RPMI 8226 cells; data not shown), this cell line was used for these experiments. Compared with control RNAi, G1P3-specific RNAi markedly downregulated IFN- $\alpha 2 b$-induced expression of G1P3 protein (Figure 8A) and mRNA (data not shown), but not the induction of an unrelated ISG, ISG 15 (Figure 8A). Under these conditions, G1P3 downregulation increased the percentage of TUNEL-posi- tive cells in untreated cells $(0.74 \%$ to $4.08 \%)$ and in IFN- $\alpha 2 \mathrm{~b}-$ treated cells (11.39\% to $40.29 \%$ ) (Figure 8 B). Consistent with this, siG1P3-transfected cells were more sensitive to IFN- $\alpha 2 b$ in viability assays (Figure 8C).

\section{Discussion}

While myeloma is considered a disease of deregulated proliferation, increased survival of malignant plasma cells may be more important for early expansion and accumulation of mutant plasma cells (22). Low labeling indices $(<1 \%)$ of myeloma cells in early stages of disease support this hypothesis (23). During early stages of disease, incipient myeloma cells in germinal centers may accumulate genetic changes that suppress apoptosis, leading to gross chromosomal abnormalities and aneuploidy $(24,25)$. Because of this central role of prosurvival pathways in myelomagenesis, delineation of the molecular mechanisms that regulate these processes could result in design of therapies targeting them.

IFN- $\alpha 2 b$ had a dual effect on myeloma cell viability; early antiapoptotic and late proapoptotic effects (Figure 1A). Despite robust signaling and induction of proapoptotic genes such as TRAIL and XAF1 (26), less than $20 \%$ of myeloma cells underwent apoptosis (Figure $1 \mathrm{~B}$ and Figure 2A and Tables 1 and 2). These observations led to the hypothesis that an ISG with prosurvival activity might be antagonizing apoptotic activity of TRAIL. Consistent with this, at early time points (24-36 hours), 
A

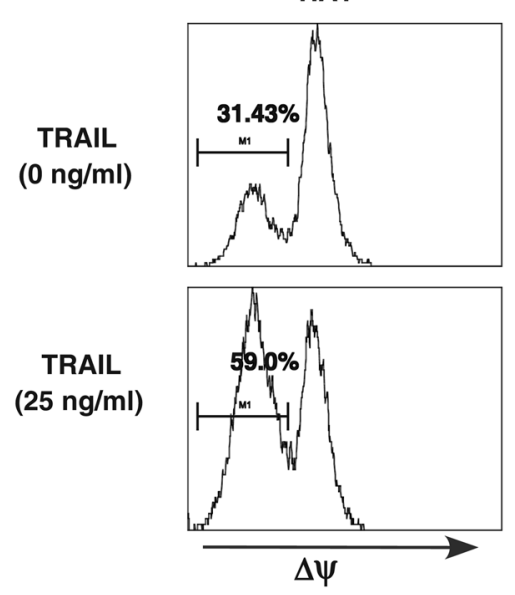

HAT-GIP3

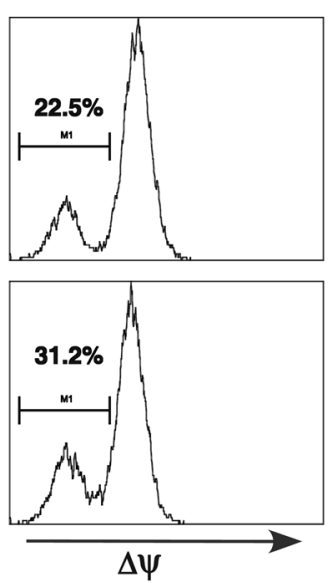

B

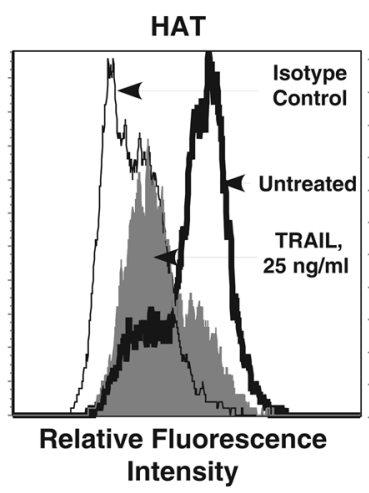

HAT-GIP3

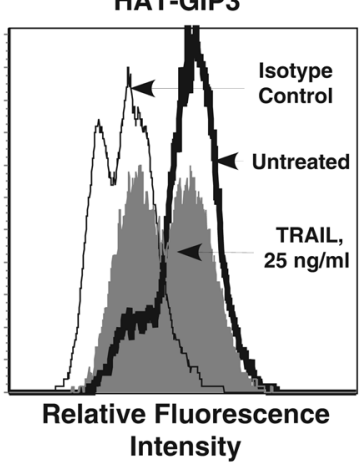

\section{Figure 6}

Ectopic G1P3 antagonized TRAIL-induced mitochondrial perturbation. (A) Ectopic G1P3 antagonized TRAIL-induced loss of $\Delta \Psi .1 \times 10^{6} \mathrm{HAT}$ (left panels) or HAT-G1P3 (right panels) cells were left untreated (top panels) or treated with TRAIL ( $25 \mathrm{ng} / \mathrm{ml}$ ) (bottom panels) for $16 \mathrm{hours}$, and $\Delta \Psi$ was measured with TMRM reagent. Three independent experiments showed similar results. (B) Constitutively expressed G1P3 antagonized mitochondrial release of cytochrome c. $1 \times 10^{6}$ HAT (left panel) or HAT-G1P3 (right panel) cells were left untreated or treated with $25 \mathrm{ng} / \mathrm{ml}$ of TRAIL. Levels of cytochrome $c$ in intact cells were measured with an FITC-conjugated cytochrome $c$ antibody (histogram with thick line). Isotypematched FITC-conjugated IgG antibody was used as a negative control (histogram with thin line). TRAIL markedly reduced the signal in HAT cells but not in HAT-G1P3 cells (filled histogram). Histograms represent results from 1 of 2 independent experiments.

IFN- $\alpha 2 \mathrm{~b}$ opposed the inhibitory effects of TRAIL on the viability of cell lines or fresh myeloma cells from 6 patients (Table 3 and Supplemental Figure 1C).

TRAIL can initiate both intrinsic and extrinsic apoptotic pathways that converge on effector caspases (caspase-3 or -7) to induce cell death $(27,28)$. In many cell types, a mitochondria-dependent signal amplification loop (intrinsic apoptotic pathway) is necessary for efficient cell death (20). At early time points, IFN- $\alpha 2 b$ antagonized TRAIL-induced intrinsic apoptosis by preserving the mitochondrial integrity of myeloma cells (Figure 3, A and B, Figure 4A, and Supplemental Figure 3). However, these antiapoptotic effects were not evident after 72 hours of cotreatment.

Expression levels of G1P3, an ISG with a putative mitochondrial localization sequence, correlated with the antiapoptotic effects of IFN- $\alpha 2 \mathrm{~b}$ (Figure 4B and Figure 5A). Constitutive retroviral expression of G1P3 in RPMI 8226 cells suppressed TRAIL-induced intrinsic apoptosis. Consistent with these findings, RNAi-mediated downregulation of G1P3 sensitized myeloma cells to IFN- $\alpha 2 b-$ induced apoptosis (Figure 8B). Similarly, knockdown of G1P3 augmented apoptotic activity of IFNs in melanoma cells (data not shown). These results suggest that G1P3 might be crucial for mediating the antagonistic effect of IFNs on apoptosis. Constitutively expressing G1P3 made RPMI 8226 cells resistant not only to TRAIL but also to late (72-96 hours) viability inhibition effects of IFN- $\alpha 2 \mathrm{~b}$ (Figure 7, B and C). Equal sensitivity of control and G1P3-overexpressing cells to the proteasome inhibitor bortezomib together with the ability of G1P3 to preserve mitochondrial stability suggested its specificity in cell death pathways involving mitochondria rather than proteasomes.

G1P3 (ISG 6-16) was one of the first identified ISGs and belongs to the FAM14 family of proteins that include FAM 14A, -B, and -C and IFI $27(29,30)$. G1P3 was potently induced by IFN- $\alpha 2 b$ not only in myeloma cell lines but also in fresh myeloma cells and has an approximate molecular weight of $13-14 \mathrm{kDa}$ (Figure 1D and
Figure 4B). Addition of a 35-amino-acid HAT sequence increased the molecular weight of recombinant G1P3 to approximately $17 \mathrm{kDa}$ in untreated cell lysates, validating its molecular weight (Figure 5B). Although constitutively expressed G1P3 localized in mitochondria (Figure 5D), whether the putative N-terminal mitochondrial localization sequence was indispensable for its mitochondrial targeting was not evaluated.

G1P3 was the first non-BH3-containing mitochondria-targeted ISG that could suppress apoptosis. Although several mitochondrial targeted proteins have been proposed to mediate the cellular apoptotic response to IFNs $(31,32)$, IFN- $\alpha 2 b(<500 \mathrm{IU} / \mathrm{ml})$ had a minimal effect on their expression in myeloma cells (data not shown), which is consistent with a recent report (33).

Unlike in cancer cells, the antiapoptotic activity of G1P3 may have a beneficial effect on IFN-mediated antiviral and innate immune responses. During viral infection, delaying early apoptosis through survival factor induction would be a viable cellular strategy to protect surrounding healthy cells from viral infection, enhancing IFN secretion, and overcoming proapoptotic activity of cytokines released into the surrounding milieu (34-36). Similarly, antiapoptotic pathways operating in immune cells play a critical role in overcoming activation-induced cell death to maintain the balance of immune response (36). Mitochondria play a critical role in eliciting antiviral response by serving as a docking site for adaptor protein complexes that are essential for IFN induction (37), suggesting a need for a stable mitochondrion that might be achieved by G1P3 induction.

On gene expression arrays, G1P3 was identified as constitutively upregulated in breast cancer $(38,39)$. Compared with primary mammary epithelial cells, G1P3 mRNA and protein were markedly increased in breast cancer cell lines (data not shown). G1P3 has also been identified recently as a constitutive protein expressed at high levels in immortalized cells and in a gastrointestinal tumor cell line, TMK1, resistant to chemotherapy-induced apoptosis (40). Additionally, low passage number melanoma cell cultures with 
A

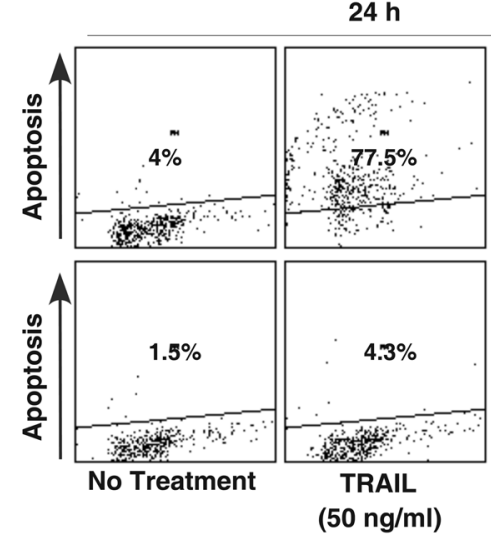

B

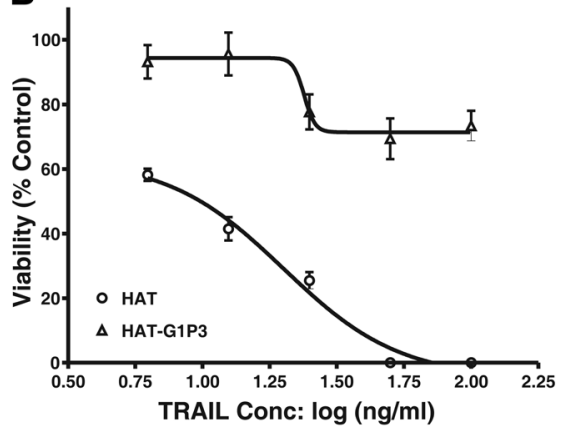

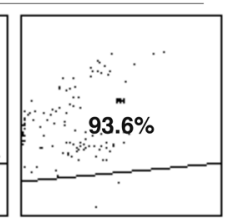

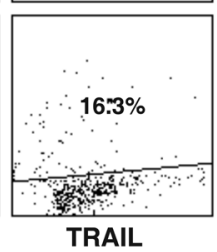

$(100 \mathrm{ng} / \mathrm{ml})$

C

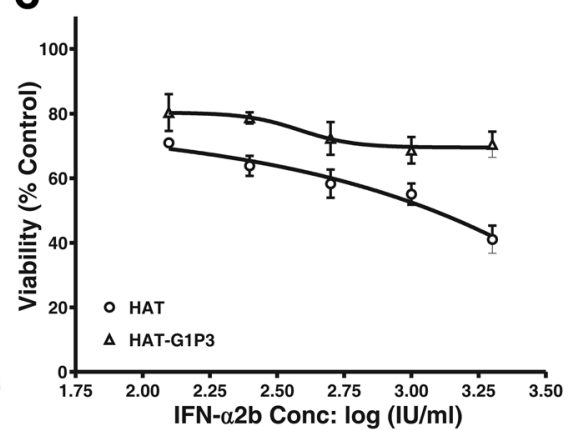

$48 \mathrm{~h}$

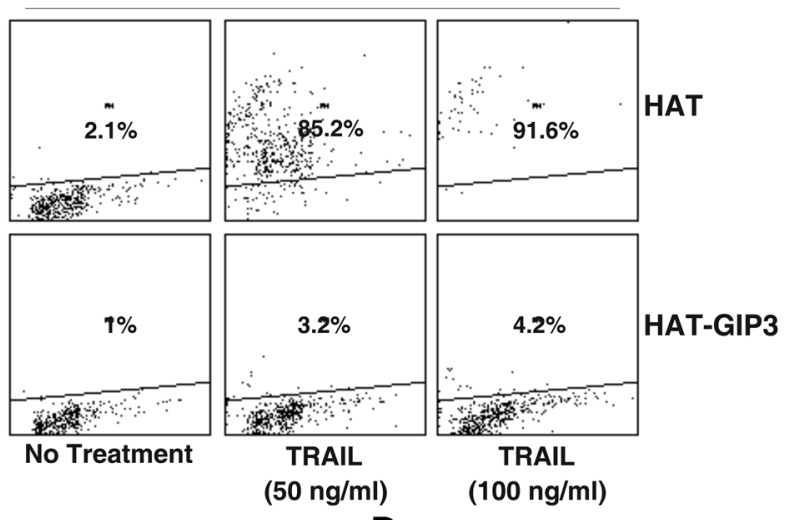

D

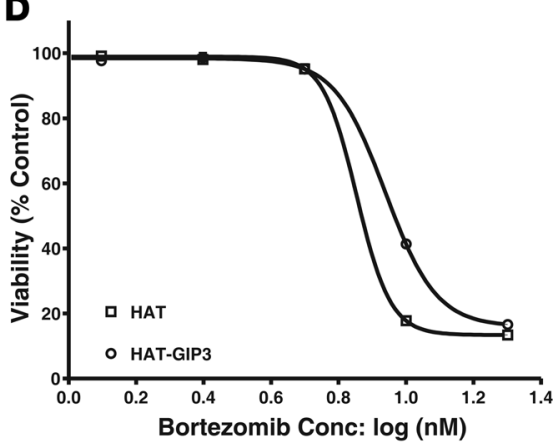

\section{Figure 7}

Effects of G1P3 overexpression on TRAIL-, IFN- $\alpha 2 b-$, and proteasome inhibitor-induced cell death. (A) G1P3-overexpressing cells were resistant to TRAIL-induced apoptosis. HAT or HAT-G1P3 cells were left untreated or treated with TRAIL (50 or $100 \mathrm{ng} / \mathrm{ml})$, and the percentage of cells undergoing apoptosis was assessed after 24 or 48 hours. Similar results were obtained in 2 other experiments. G1P3-overexpressing cells were resistant to TRAIL (B) and IFN- $\alpha 2 b$ (C) but not to bortezomib (D). HAT or HAT-G1P3 cells were treated with increasing concentrations of TRAIL for 96 hours or bortezomib for 72 hours. $E D_{50}$ was calculated using nonlinear regression analysis using Prism 4.0 software. Graph represents nonlinear regression analysis results from 1 of 2 independent experiments. Each point on the graph is mean \pm SD of 6 replicates. conc, concentration.

higher levels of induced G1P3 were less sensitive to the antiproliferative effects of IFN- $\beta$ (data not shown).

Besides IFNs, TRAIL can induce G1P3 mRNA in tumor cells (41). Introduction of recombinant TRAIL and its receptor agonist antibodies into clinical trials emphasizes the need for further investigation of G1P3. Compared with cell lines, TRAIL was less effective in inhibiting the viability of fresh myeloma cells (Table 3; refs. 42, 43). Lack of detection of G1P3 protein at the basal level in fresh myeloma cells suggests that signals other than G1P3 may be critical in eliciting survival advantages in these cells (Figure 4B). Under these conditions, IFN- $\alpha 2 \mathrm{~b}$ induced the expression of G1P3 and antagonized the effects of TRAIL on fresh myeloma cell viability (Figure 4B and Table 3), suggesting that either the deregulated or the induced expression of G1P3 could lead to apoptosis resistance in tumor cells. Therefore, the current findings may provide an explanation for discrepant reports of effectiveness of IFN- $\alpha 2 b$ in myeloma (6). Better characterization of G1P3 could provide new insights into the role of G1P3 survival pathways in myeloma or other malignancies and induction of resistance to various therapeutic modalities.

\section{Methods}

Cell lines. Human multiple myeloma cell lines (HMCLs) RPMI 8226, U266, and NCI-H929 were purchased from ATCC and propagated in recommended media.
Reagents and antibodies. Recombinant IFN- $\alpha 2 \mathrm{~b}$ purified to homogeneity (Schering-Plough) had a specific activity of $2.6 \times 10^{8} \mathrm{IU} / \mathrm{mg}$ of protein. TRAIL was obtained from PeproTech. Caspase-8, caspase-3, Cox IV, and MST1 antibodies were from Cell Signaling Technology. Other antibodies and their sources (in parentheses) are as follows; anti-phospholipase scramblase (a kind gift from B. Dong, The Cleveland Clinic), anti-G1P3 (a kind gift from H. Tahara, The Hiroshima University, Hiroshima, Japan), anti-Stat1 (BD Biosciences), anti-phospho-Stat1 (Tyr 701; Upstate), antiDFF45A (BD Biosciences), anti-PARP (BIOMOL), anti- $\beta$-actin (SigmaAldrich), and monoclonal anti-ISG15 antibody (44).

Viability assays. HMCLs were seeded in 96-well plates at a concentration of $4 \times 10^{5}$ cells $/ \mathrm{ml}$ and incubated for 24-96 hours with various concentrations of IFN- $\alpha 2 b$ or TRAIL $(6 \times 150 \mu$ replicates at each concentration). At the end of incubation, viability was measured either by Alamar blue assay (Invitrogen) or by WST1 reagent (Roche Applied Science) according to the manufacturers' protocol using a 96-well plate reader (Fisher Scientific). The $\mathrm{IC}_{50}$ was calculated by nonlinear regression analysis after converting the drug concentrations into log-X using Prism 4.0 software (GraphPad Software Inc.).

Fresh myeloma cell isolation and viability measurement. Bone marrow aspirates were collected from multiple myeloma patients after appropriate consent was obtained as per The Cleveland Clinic institutional guidelines. The MNC fraction was isolated by density gradient centrifugation in lymphocyte separation media (Cellgro) as per the manufacturer's instructions. MNCs $\left(1 \times 10^{5}\right)$ 

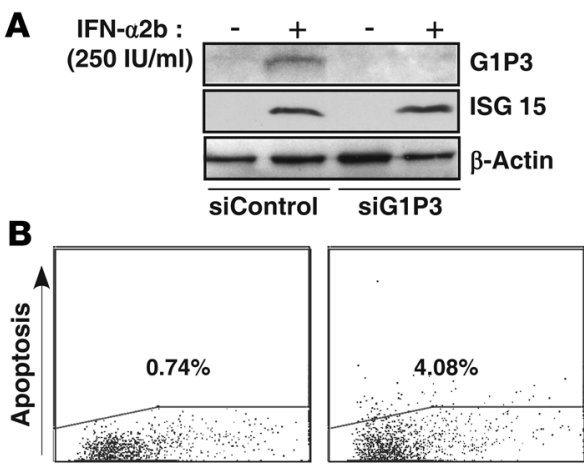

IFN- $\alpha 2 b$ (0 IU/ml)

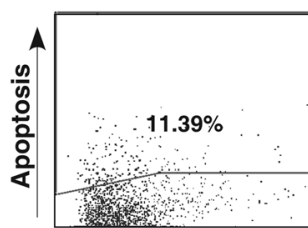

siControl

C

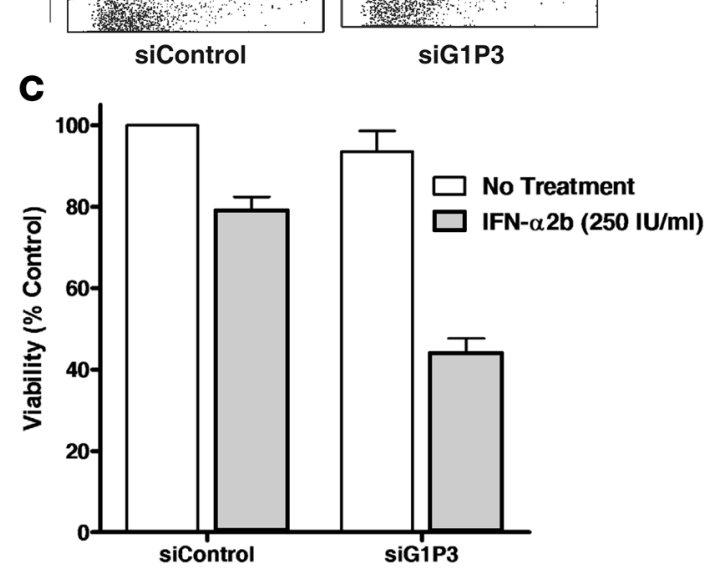

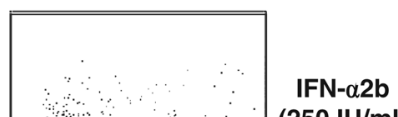

$(250 \mathrm{IU} / \mathrm{ml})$

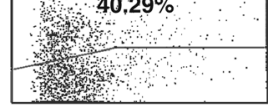

siG1P3

\section{(250}

(1)

were then left untreated or treated with IFN- $\alpha 2 \mathrm{~b}(62.5 \mathrm{IU} / \mathrm{ml}$ or $250 \mathrm{IU} / \mathrm{ml})$, TRAIL (400 ng/ml), or both in combination for 24 hours. The percentage of dead or viable primary tumor cells in untreated control and treatment groups was determined by staining for 15 minutes at room temperature with 7AAD (BD Biosciences) and FITC-conjugated CD138 antibody (Diaclone Research), followed by flow cytometry. The relative percentage of CD138 cells in treatment groups with respect to untreated cultures was calculated.

$\mathrm{CD} 138^{+}$cells were enriched from MNCs using microbeads conjugated with an anti-CD138 antibody and MACS column (Miltenyi Biotec) according to the manufacturer's protocol. The purity of the cells was assessed by flow cytometry using a PE-conjugated CD138 antibody with a PE-conjugated IgG as isotype control.

Mitochondrial fractionation and potential measurement. Cytosolic and mitochondrial fractions for Western blots were prepared from $1 \times 10^{7}$ cells by differential centrifugation using a mitochondrial isolation kit for cultured cells according to manufacturer's instructions (Pierce). For measuring $\Delta \Psi$, enriched CD $138^{+}$cells (>85\% pure) or RPMI 8226 cells were harvested and resuspended in $1 \mathrm{nM}$ TMRM dye for 10 minutes at room temperature in the dark. The shift in TMRM intensity was measured by flow cytometry with a Epics XL-MCL flow cytometer (Beckman Coulter Inc.), and FCS EXPRESS 2.0 software (De Novo Software) was used for data analysis.

Apoptosis and caspase activity assays and PARP cleavage. TUNEL assay was performed as described previously (12). Caspase-3/7 or caspase- 8 activity in cells treated with IFN- $\alpha 2 b$, TRAIL, or both in combination was measured by caspase-Glo assay reagent (Promega) according to the manu-

\section{Figure 8}

Downregulation of G1P3 sensitized myeloma cells to apoptosis and antiviability effects of IFN- $\alpha 2 b$. (A) Stealth RNAi against G1P3 downregulated IFN- $\alpha 2 b$-induced G1P3 expression. U266 cells were transfected with either a scrambled stealth RNAi (siControl) or a G1P3 stealth RNAi (siG1P3). Sixteen hours after transfection, cells were treated with $250 \mathrm{IU} / \mathrm{ml}$ IFN- $\alpha 2 \mathrm{~b}$ for 24 hours, and $30 \mu \mathrm{g}$ WCEs from untreated and treated cells were immunoblotted to assess G1P3 expression. (B) G1P3 downregulation sensitized myeloma cells to IFN- $\alpha 2 b$-induced apoptosis. Forty-eight hours after IFN- $\alpha 2 b$ treatment, the percentage of cells undergoing apoptosis was measured by TUNEL assay as in Figure 2A. Similar results were obtained in 2 other experiments. (C) G1P3 downregulation augmented the antiviability activity of IFN- $\alpha 2 b$. Viability of cells transfected with RNAi followed by IFN- $\alpha 2 b$ treatment for 48 hour was measured by Alamar blue assay. Each bar in the graph represents mean \pm SEM of 3 independent experiments done in triplicate.

facturer's instructions. Luminescence of caspase-Glo reaction was measured using a 96-well luminometer (VICTOR 1420 multilabel counter; Wallac Instruments). Untreated or treated cells were lysed in the buffer (62.5 mM Tris- $\mathrm{HCl}, 10 \%$ glycerol, $6 \mathrm{M}$ urea, and 5\% $\beta$-mercaptoethanol) and immunoblotted with monoclonal anti-PARP antibody (BIOMOL).

Immunoblot analysis. WCEs were made by lysing $1 \times 10^{6}$ treated or untreated cells with RIPA buffer (Sigma-Aldrich) containing $1 \times$ protease inhibitor cocktail (Calbiochem). WCE (10-40) $\mu \mathrm{g}$ was subjected to immunoblot analysis as described previously (12).

$R N A$ isolation, $c D N A$ synthesis, and real-time RT-PCR. RNA was isolated using SV Total RNA Isolation System (Promega), and cDNA was prepared with Mo-MLV reverse transcriptase (Promega) according to the manufacturer's instructions. Taqman expression primers and ABI PRISM Sequence Detection Instrument 7500 (Applied Biosystems) were used for real-time RT-PCR. Fold change in target genes was calculated relative to human GAPDH.

cDNA cloning and ectopic expression of G1P3. G1P3 cDNA was amplified from RNA of IFN- $\alpha 2 b$-treated $(250 \mathrm{IU} / \mathrm{ml})$ RPMI 8226 cells by nested PCR with 5'-GTCGACGGATCCATGCGGCAGAAG-3' (G1P3-BamH1.F) as forward, 5'-CTAGCGAGACCTACTCCTCATCCTCCTCACTA-3'(G1P3-Bsa1.R) and 5'-GTGAATTCGCGGCCGCAAGCTTAGTTAGATCTAGCGAGACCT3' (G1P3.EcoR1.R) as reverse primers. The amplicon was subcloned into BamH1 and EcoR1 in pHAT10 vector (BD Biosciences - Clontech) to generate the HAT-G1P3 fusion construct. The entire HAT-G1P3 open reading frame was sequence verified and then subcloned into Age1 and EcoR1 sites of PQCXIP retroviral expression vector (BD Biosciences - Clontech). HAT at $\mathrm{N}$-terminal and putative structural elements was derived from primary amino acid sequence analysis with protean software (Lasergene Inc.; DNASTAR). The pantropic virion production and RPMI 8226 cell transduction were performed using Calphos Mammalian Transfection kit (BD Biosciences - Clontech) according to the manufacturer's protocol. Single-cell clones were isolated with puromycin $(1 \mu \mathrm{g} / \mathrm{ml})$ selection. The HAT clones were screened by RT-PCR using 5'-GCTATGACCATGATTACGCCA-3' (HAT.F) and 5'-AAGTCGACGGATCCATGCGGC-3' (HAT.R) primers, and HATG1P3 clones were screened with HAT.F and G1P3-Bsa1.R primers. Highexpressing HAT or HAT-G1P3 clones were identified by real-time RT-PCR with a G1P3-specific Taqman probe (Applied Biosystems).

Stealth RNAi. For downregulation of G1P3 expression, U266 cells were transfected using Amaxa transfection system (Amaxa Biosystems) with $20 \mathrm{nM}$ of G1P3 specific stealth RNAi (5'-GGCAGCAGCGUCGUCAUAGGUAAUA-3') or a scrambled RNAi sequence (5'-GGCCAGCGUCGUCCAUAGGUAAGAUA-3').

Microarray analysis. Microarray analysis was performed using Affymetrix human genome U133A array as described previously (45). The microarray scanned image and intensity files (.cel files) were imported into Rosetta 
Resolver gene expression analysis software version 3.2 (Rosetta Inpharmatics). Error models were applied, and ratios were built for each treatment array versus its respective vehicle control.

Statistics. Two-tailed Student's $t$ test and 1-way repeated-measures ANOVA followed by all pairwise multiple comparison procedures (Holmes-Sidak method) were performed using SigmaStat 3.5 software, and a $P$ value of less than 0.05 was considered significant.

\section{Acknowledgments}

We would like to thank George R. Stark and Ram Ganapathi, The Cleveland Clinic, for critical reading; and Christine HealanGreenberg, Abbott Research Laboratories, and Barbara S. Jacobs and Dustin S. Thomas, The Cleveland Clinic, for technical help.
Polyclonal anti-G1P3 antiserum was a kind gift from Hidetoshi Tahara, The Hiroshima University, Japan. This work was funded in part by the American Cancer Society pilot grant to V. Cheriyath and NIH grant NC1 RO1 CA090914-04 to E.C. Borden.

Received for publication December 1, 2006, and accepted in revised form June 26, 2007.

Address correspondence to: Ernest C. Borden, The Cleveland Clinic, Taussig Cancer Center, Center for Hematology and Oncology Molecular Therapeutics, R40, 9500 Euclid Avenue, Cleveland, Ohio, 44195, USA. Phone: (216) 444-8183; Fax: (216) 636-2498; E-mail: bordene@ccf.org.
1. Urabe, A. 1994. Interferons for the treatment of hematological malignancies. Oncology. 51:137-141.

2. Borden, E., Lindner, D., Dreicer, R., Hussein, M., and Peereboom, D. 2000. Second-generation interferons for cancer: clinical targets. Semin. Cancer Biol. 10:125-144.

3. Schaar, C., et al. 2005. Interferon-alpha as maintenance therapy in patients with multiple myeloma. Ann. Oncol. 16:634-639.

4. Borden, E. 1994. Innovative treatment strategies for non-Hodgkin's lymphoma and multiple myeloma. Semin. Oncol. 21(6 Suppl. 14):14-22.

5. Juturi, J., et al. 2001. High, intermittent dose of all-trans retinoic acid in combination with alphainterferon for advanced multiple myeloma. Haematologica. 86:776-777.

6. Peest, D., et al. 1996. Cytokine therapy in multiple myeloma. Br. J. Haematol. 94:425-432.

7. Ferlin-Bezombes, M., et al. 1998. IFN-alpha is a survival factor for human myeloma cells and reduces dexamethasone-induced apoptosis. J. Immunol. 161:2692-2699.

8. Otsuki, T., et al. 1998. Human myeloma cell apoptosis induced by interferon-alpha. Br. J. Haematol. 103:518-529.

9. Chen, Q., et al. 2001. Apo2L/TRAIL and Bcl-2related proteins regulate type I interferoninduced apoptosis in multiple myeloma. Blood. 98:2183-2192.

10. Dimberg, L., et al. 2005. Ectopic and IFN-induced expression of Fas overcomes resistance to Fasmediated apoptosis in multiple myeloma cells. Blood. 106:1346-1354.

11. Gomez-Benito, M., et al. 2005. Apo2L/TRAIL is an indirect mediator of apoptosis induced by interferon-alpha in human myeloma cells. FEBS Lett. 579:6217-6222.

12. Chawla-Sarkar, M., Leaman, D., Jacobs, B., and Borden, E. 2002. IFN-beta pretreatment sensitizes human melanoma cells to TRAIL/Apo2 ligandinduced apoptosis. J. Immunol. 169:847-855.

13. Crowder, C., Dahle, O., Davis, R., Gabrielsen, O., and Rudikoff, S. 2005. PML mediates IFN-alphainduced apoptosis in myeloma by regulating TRAIL induction. Blood. 105:1280-1287.

14. Liu, P., Oken, M., and Van, N.B. 1999. Interferonalpha protects myeloma cell lines from dexamethasone-induced apoptosis. Lenkemia. 13:473-480.

15. Davies, F., et al. 2003. Insights into the multistep transformation of MGUS to myeloma using microarray expression analysis. Blood. 102:4504-4511.
16. Graves, J., et al. 1998. Caspase-mediated activation and induction of apoptosis by the mammalian Ste20-like kinase Mst1. EMBO J. 17:2224-2234.

17. Liu, X., et al. 1998. The 40-kDa subunit of DNA fragmentation factor induces DNA fragmentation and chromatin condensation during apoptosis. Proc. Natl. Acad. Sci. U. S. A. 95:8461-8466.

18. Kumar, S. 1997. The apoptotic cysteine protease CPP32. Int. J. Biochem. Cell Biol. 29:393-396.

19. Green, D., and Reed, J. 1998. Mitochondria and apoptosis. Science. 281:1309-1312.

20. Zhang, L., and Fang, B. 2005. Mechanisms of resistance to TRAIL-induced apoptosis in cancer. Cancer Gene Ther. 12:228-237.

21. Cereghetti, G., and Scorrano, L. 2006. The many shapes of mitochondrial death. Oncogene. 25:4717-4724.

22. Hallek, M., Bergsagel, P., and Anderson, K. 1998. Multiple myeloma: increasing evidence for a multistep transformation process. Blood. 91:3-21.

23. Bergsagel, P.L., and Kuehl, W.M. 2001. Chromosome translocations in multiple myeloma. Oncogene. 20:5611-5622.

24. Fonseca, R., et al. 2002. Genomic abnormalities in monoclonal gammopathy of undetermined significance. Blood. 100:1417-1424.

25. Kuehl, W., and Bergsagel, P. 2002. Multiple myeloma: evolving genetic events and host interactions. Nat. Rev. Cancer. 2:175-187.

26. Chawla-Sarkar, M., et al. 2003. Apoptosis and interferons: role of interferon-stimulated genes as mediators of apoptosis. Apoptosis. 8:237-249.

27. Hengartner, M.O. 2000. The biochemistry of apoptosis. Nature. 407:770.

28. Kelley, S., and Ashkenazi, A. 2004. Targeting death receptors in cancer with Apo2L/TRAIL. Curr. Opin. Pharmacol. 4:333-339.

29. Kelly, J., et al. 1986. Characterization of a human gene inducible by alpha- and beta-interferons and its expression in mouse cells. EMBO J. 5:1601-1606.

30. Itzhaki, J., et al. 1992. Targeted breakage of a human chromosome mediated by cloned human telomeric DNA. Nat. Genet. 2:283.

31. Panaretakis, T., Pokrovskaja, K., Shoshan, M., and Grander, D. 2003. Interferon-alpha-induced apoptosis in U266 cells is associated with activation of the proapoptotic Bcl-2 family members Bak and Bax. Oncogene. 22:4543-4556.

32. Sun, Y., and Leaman, D. 2005. Involvement of Noxa in cellular apoptotic responses to interferon, double-stranded RNA, and virus infection. J. Biol. Chem.
280:15561-15568.

33. Jourdan, M., De, V.J., Mechti, N., and Klein, B. 2000. Regulation of $\mathrm{Bcl}-2$-family proteins in myeloma cells by three myeloma survival factors: interleukin6 , interferon-alpha and insulin-like growth factor 1 . Cell Death Differ. 7:1244-1252.

34. Teodoro, J., and Branton, P. 1997. Regulation of apoptosis by viral gene products. J. Virol. 71:1739-1746.

35. Hardwick, J. 1998. Viral interference with apoptosis. Semin. Cell Dev. Biol. 9:339-349.

36. Zhang, X.R., et al. 2003. Reciprocal expression of APO2L/TRAIL and CD95L in Th1 and Th2 cells: role of apoptosis in $\mathrm{T}$ helper subset differentiation. Cell Death Differ. 10:203-210.

37. Seth, R., Sun, L., Ea, C., and Chen, Z. 2005. Identification and characterization of MAVS, a mitochondrial antiviral signaling protein that activates NF-kappaB and IRF 3. Cell. 122:669-682.

38. Sorbello, V., et al. 2003. Quantitative real-time RTPCR analysis of eight novel estrogen-regulated genes in breast cancer. Int. J. Biol. Markers. 18:123-129.

39. Shen, D., He, J., and Chang, H.R. 2005. In silico identification of breast cancer genes by combined multiple high throughput analyses. Int. J. Mol. Med. 15:205-212.

40. Tahara, E.J., et al. 2005. G1P3, an interferon inducible gene 6-16, is expressed in gastric cancers and inhibits mitochondrial-mediated apoptosis in gastric cancer cell line TMK-1 cell. Cancer Immunol. Immunother. 54:729-740.

41. Kumar-Sinha, C., Varambally, S., Sreekumar, A., and Chinnaiyan, A. 2002. Molecular cross-talk between the APO2L/TRAIL and interferon signaling pathways. J. Biol. Chem. 277:575-585.

42. Lincz, L.F., Yeh, T.X., and Spencer, A. 2001. TRAILinduced eradication of primary tumour cells from multiple myeloma patient bone marrows is not related to TRAIL receptor expression or prior chemotherapy. Leukemia. 15:1650-1657.

43. Mitsiades, C.S., et al. 2001. TRAIL/Apo2L ligand selectively induces apoptosis and overcomes drug resistance in multiple myeloma: therapeutic applications. Blood. 98:795-804.

44. D'Cunha, J., et al. 1996. In vitro and in vivo secretion of human ISG15, an IFN-induced immunomodulatory cytokine. J. Immunol. 157:4100-4108.

45. Glaser, K.B., et al. 2003. Gene expression profiling of multiple histone deacetylase (HDAC) inhibitors: defining a common gene set produced by HDAC inhibition in T24 and MDA carcinoma cell lines. Mol. Cancer Ther. 2:151-163. 